\title{
STATIC TEST ON FULL SCALE RAMMED EARTH BUILDING WITH MESH-WRAP RETROFITTING STRATEGY
}

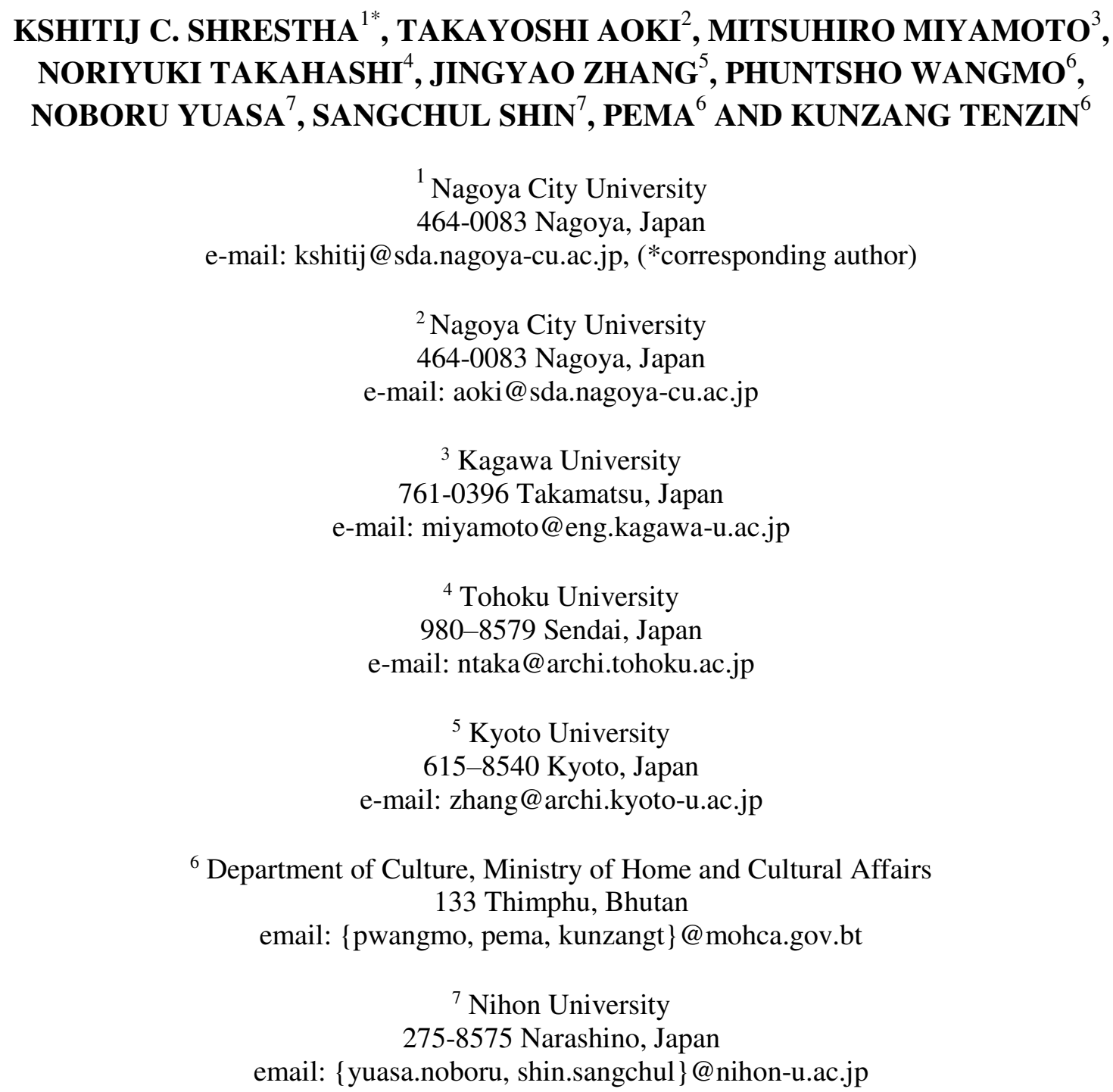

Keywords: Rammed Earth Structure, Composite Masonry, Full-scale test, Retrofitting

Abstract. This paper reports the experimental campaign for static tests performed on unreinforced (URE) and mesh retrofitted (RRE) full scale rammed earth building. Amongst varying building patterns of traditional rammed earth houses found in Bhutan, a two-storied building with a full solid wall (small openings) on the first floor and larger opening in the front facade of the second floor was chosen. The proposed mesh-wrap retrofitting of the walls involved the use of standard mild steel welded mesh as the main mesh, M-Mesh (Ø $1.8 \mathrm{~mm}$ and 
$34 \mathrm{~mm} \mathrm{c/c} \mathrm{spacing)} \mathrm{and} \mathrm{light} \mathrm{and} \mathrm{galvanized} \mathrm{welded} \mathrm{mesh} \mathrm{as} \mathrm{a} \mathrm{lapping} \mathrm{mesh,} \mathrm{L-Mesh} \mathrm{(Ø} 1.45$ $\mathrm{mm}$ and $28 \mathrm{~mm} \mathrm{c/c} \mathrm{spacing)} \mathrm{provided} \mathrm{at} \mathrm{the} \mathrm{corners} \mathrm{and} \mathrm{along} \mathrm{the} \mathrm{height} \mathrm{of} \mathrm{the} \mathrm{walls.} \mathrm{The}$ static test loading protocol involved the displacement controlled loading with drift-control over the building. Cracks and damage observations were made at the storey drift ratios of: 1/2000, 1/1000, 1/750, 1/500 for URE building. The same URE building was retrofitted afterward and retested as RRE to storey drift ratios of: 1/2000, 1/1000, 1/750, 1/500, 1/250, 1/150, 1/100 and 1/75. The mesh retrofitting is found effective in both damage control as well as strength enhancement over the unreinforced one. The URE specimen showed a clear opening of shear and vertical cracks in the in-plane loaded walls near the openings and Jugshing holes. For the RRE specimen, cracks dispersed over a large region of the in-plane loaded walls. No delamination of mesh-wrap was observed, showing the effectiveness of the proposed technique. The RRE specimen showed enhancement in base shear by 2.5 times, ductility 2.3 times, and energy absorption 12 times the URE counterpart.

\section{$1 \quad$ INTRODUCTION}

Rammed earth (RE) construction is one of the most dominant traditional and historical construction practices and is mainly popular in the western part of Bhutan. These traditional buildings represent not only the unique architecture of Bhutan but also expresses the social and economic viability of the community. However, the past earthquake of magnitude M6.9, which occurred on September 18, 2011, near Nepal-India border destroyed remarkable number of rammed earth structures in Bhutan. Several pastresearch works studied the behavior of RE wall components in both in clearly state the vulnerabilitie wall components.

The present work tries to assess the behavi building through drift-eontrolled push-over st

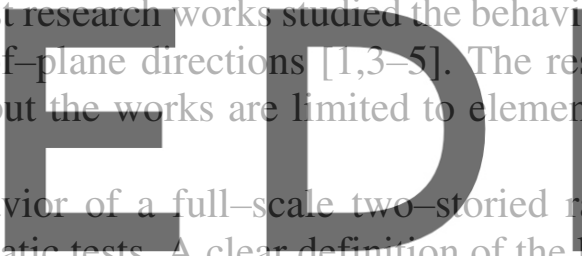

$\mathrm{RE}$ is presented to identify the different damage levels in RE building based on the full scale

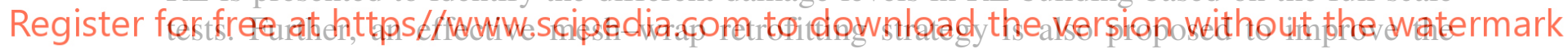
seismic resilience of RE. The proposed work will help to contribute towards strengthening the existing traditional and historical rammed earth houses, which comprises a significant percentage of the current building stock in the country.

\section{TEST PROGRAM}

\subsection{Materials}

\subsubsection{Rammed earth}

The rammed earth (RE) material used in construction was from the nearby local site. The earth soil used for ramming included reddish-white clay with small pebbles. The grain size distribution of the RE used showed a particle size range of $0-10 \mathrm{~mm}$. More details on the soil materials and particle size distribution can be found in Wangmo et al. [3]. For material characterization, RE cylindrical core samples were extracted from the test specimens using core drilling machine with diamond core bits for dry core drilling. In total, twelve of these cylindrical core samples for each specimen type were tested to measure compressive strength (ASTM C39) 
Kshitij C. Shrestha, Takayoshi Aoki, Mitsuhiro Miyamoto, Noriyuki Takahashi, Jingyao Zhang, Phuntsho Wangmo, Noboru Yuasa, Sangchul Shin, Pema and Kunzang Tenzin

and splitting tensile strength (ASTM C496). Table 1 lists the properties of RE from material characterization.

Table 1: Material characterization of rammed earth block

\begin{tabular}{ccccccccc}
\hline Specimen & \multicolumn{4}{c}{ URE } & \multicolumn{4}{c}{ RRE } \\
\hline Unit & $\begin{array}{c}\rho_{\mathrm{b}} \\
\left(\mathrm{kg} / \mathrm{m}^{3}\right)\end{array}$ & $\begin{array}{c}f_{\mathrm{c}} \\
(\mathrm{MPa})\end{array}$ & $\begin{array}{c}f_{\mathrm{t}} \\
(\mathrm{MPa})\end{array}$ & $\begin{array}{c}E \\
(\mathrm{MPa})\end{array}$ & $\begin{array}{c}\rho_{\mathrm{b}} \\
\left(\mathrm{kg} / \mathrm{m}^{3}\right)\end{array}$ & $\begin{array}{c}f_{\mathrm{c}} \\
(\mathrm{MPa})\end{array}$ & $\begin{array}{c}f_{\mathrm{t}} \\
(\mathrm{MPa})\end{array}$ & $\begin{array}{c}E \\
(\mathrm{MPa})\end{array}$ \\
\hline Mean & 1837 & 0.94 & 0.12 & 249 & 2024 & 1.65 & 0.17 & 389 \\
\hline Std. Dev. & 33 & 0.12 & 0.02 & 58 & 13 & 0.15 & 0.03 & 55 \\
\hline
\end{tabular}

\subsubsection{Timber}

Wooden beam joists, $125 \mathrm{~mm}$ wide $150 \mathrm{~mm}$ deep of mixed conifer found in Bhutan, were used at the floor levels. The material properties for timber can be found in Shrestha et al. [5].

\subsubsection{Mesh retrofitting components}

Two types of wire mesh were used, standard mild steel welded mesh as the main mesh, MMesh ( $\varnothing 1.8 \mathrm{~mm}$ and $34 \mathrm{~mm} \mathrm{c} / \mathrm{c}$ spacing) and light and galvanized welded mesh as a lapping mesh, L-Mesh ( $\varnothing 1.45 \mathrm{~mm}$ and $28 \mathrm{~mm} \mathrm{c} / \mathrm{c}$ spacing) at the corners and along the height of the walls. A cement (OPC) plaster of ratio 1:3 (cement: sand) was applied to the RM wall substrate. The average compressive and tensile strength of the cement plaster was $17.38 \mathrm{MPa}$ and 1.59

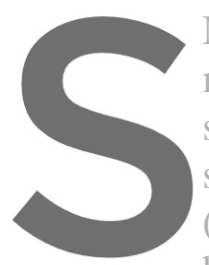
MPa, respectively. It should be mud plaster over the cent stabilized mud plaster specimen during the wirt (30 $\mathrm{mm}$ thick) is far greater than that of rammed between the two materials. It should be noted that the results reported are for the first set of series of planned tests, and authors. will focus their future works to scrutinize these arguments Register for free at https//WwW.scipedia.com to download the version without the watermark

For material characterization of the retrofitting components, test coupons (Figure 1a) 200 $\mathrm{mm}$ long, $50 \mathrm{~mm}$ wide, and $30 \mathrm{~mm}$ thick were prepared for Mi-Miesh and tested under tensile loading with clevis type grip as shown in Figure 1b. Figures 1c and 1d show the test results for the tensile coupon tests. The plot in Figure 1c shows an initially high stiffness and drop in load at around 0.6-1 $\mathrm{MPa}$ stress representing the initial cracking in the mortar. Afterward, the stiffness reduces significantly, and the crack widens with further slip along the length of the coupon (Figure 1d). The authors will generalize these tensile test coupon tests to incorporate in the material characteristics for finite element modeling generation in their future works.

\subsection{Test specimen details}

\subsubsection{Prototype unreinforced rammed earth specimen (URE)}

The full-scale tests were carried out on a prototype Bhutanese traditional house. The building represents a traditional residential house of Bhutan following the typical architectural pattern with limited openings at first floor level and a large opening on the second floor of the building's front facade. The prototype has a floor area of $8.1 \mathrm{~m} \times 5.4 \mathrm{~m}$ as shown in Figure 2, 
with three rooms on each floor. The second floor level has a large opening in the front facade, termed as rabsey. The URE specimen was tested after four months of drying. The drying period was decided based on the authors' previous works [6].
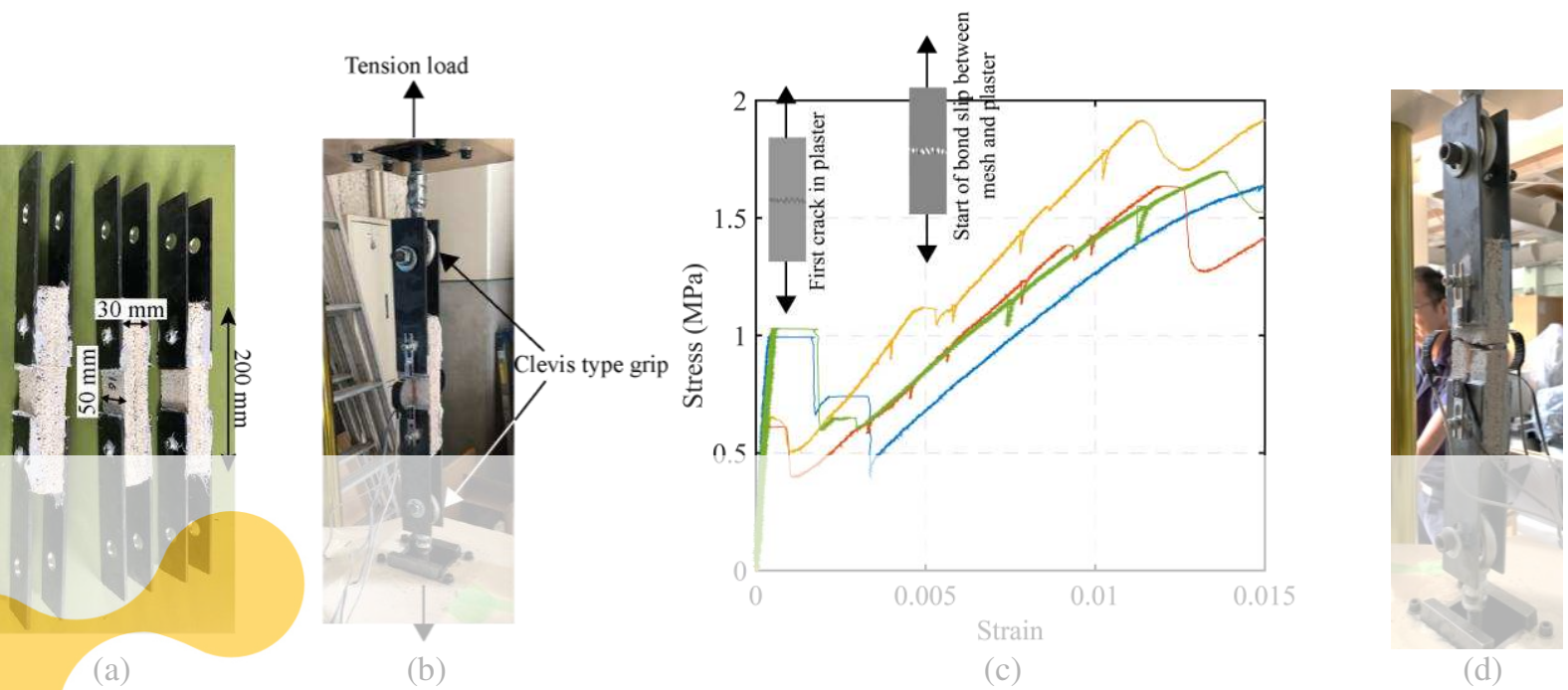

Figure 1: Material characterization tests for mesh retrofitting component: (a) Test coupons epoxy-bonded at the ends to steel plates, (b) Test set-up with clevis type grips, (c) Tensile stress versus strain plots for tensile coupon

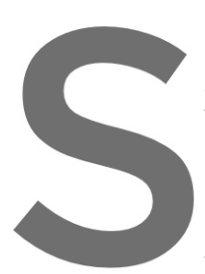
tests of M-Mesh, (d) Typical failure mode at the end of coupon test

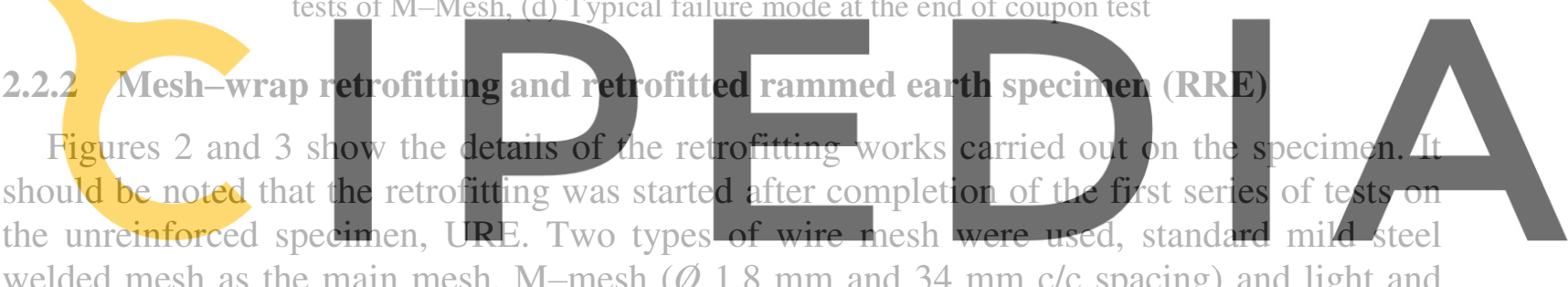
welded mesh as the main mesh, M-mesh $(\varnothing 1.8 \mathrm{~mm}$ and $34 \mathrm{~mm} \mathrm{c} / \mathrm{c}$ spacing) and light and

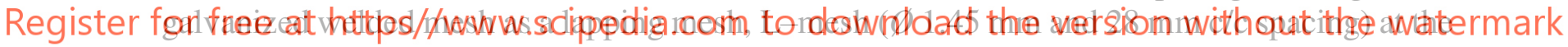
corners and along the height of the walls. A lapping length of $300 \mathrm{~mm}$ was provided in the vertical direction in regular intervals, while $600 \mathrm{~mm}$ lap was provided in the horizontal direction at the corners. First, the mesh was placed on the walls using U-hooks. This was followed by clamping of mesh to the walls using $12 \mathrm{~mm}$ diameter rods inserted through the jugshing holes and bolted with nuts, as shown in Figures 2 and 3a. Finally, a $30 \mathrm{~mm}$ thick cement plaster (cement and sand at 1:3) was applied over the mesh. Prior to plastering, the wall's surface was pretreated using cement slurry (thin mix of cement and water). For the floor joist, $\mathrm{X}$-bracing with timber of size $75 \mathrm{~mm} \times 75 \mathrm{~mm}$ was provided to connect the floor joists. The $\mathrm{X}$-bracings were bolted to the floor joists at the center and the ends. It should be noted that only the inplane loaded walls (east and west elevations) were retrofitted as shown in Figure 2, with an extension of the L-mesh to the north and south elevations up to $600 \mathrm{~mm}$. The RRE specimen was tested after three months of curing.

\subsection{Test set-up and instrumentations}

The test set-up for the static test is illustrated in Figure 4a. Two $1000 \mathrm{kN}$ capacity jacks were positioned at the second-floor level (2FL), and the other two of $500 \mathrm{kN}$ capacity were placed at 
the roof-floor level (RFL). One end of the jack was connected to the reaction wall through the built-up section and the other end to the test specimen's wall face through a $9.5 \mathrm{~m}$ long Hsection. There were two $9.5 \mathrm{~m}$ long $\mathrm{H}$-sections installed at each floor level, resting on support systems that allow them to slide along the support with the jacks. The static jack is a hydraulic system that was manually operated. The instrumentations are illustrated in Figure 4a. The instrumentation involves load cells installed on hydraulic jacks to measure the applied forces. The displacement was measured using 14 displacement transducers: ten laser transducers (Keyence, IL-300) and four strain gauge type transducers (TML SDP-100C, SDP-50C) at three different levels (base, 2FL, and RFL) of the test specimen both at the loading and the free side. A multi-channel dynamic strainmeter DS-50A was used for data logging with the LAN interface setting. The data sampling rate was set at $100 \mathrm{~Hz}$.
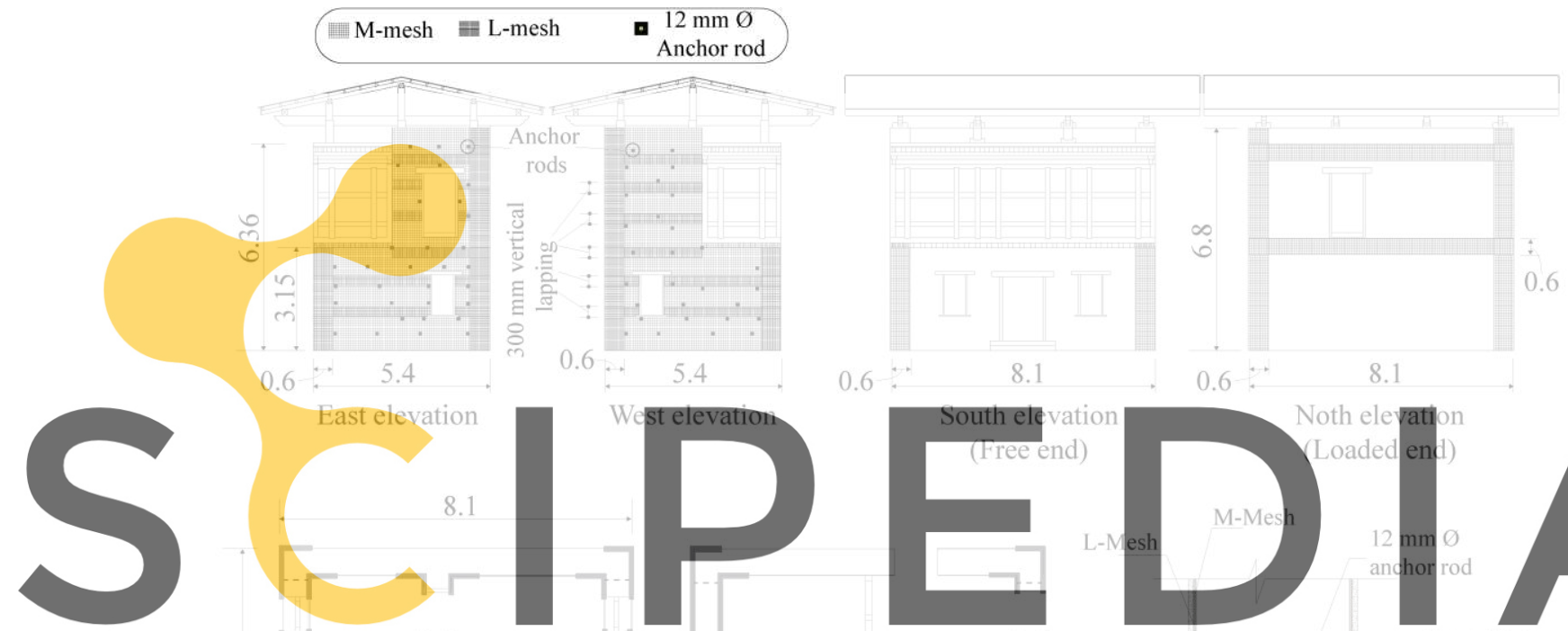

Register for free at https//www.scipedia.com to download the version withoutnthe kwatermark
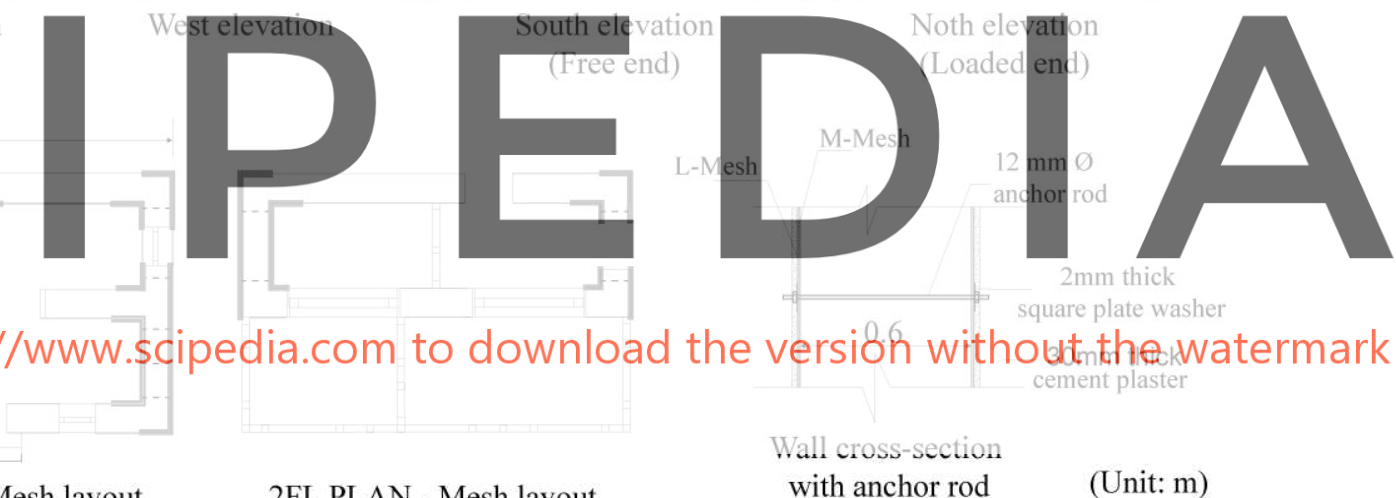
cement plaster

1FL PLAN - Mesh layout

2FL PLAN - Mesh layout

with anchor rod

(Unit: m)

Figure 2: Prototype retrofitted rammed earth building specimen (RRE)

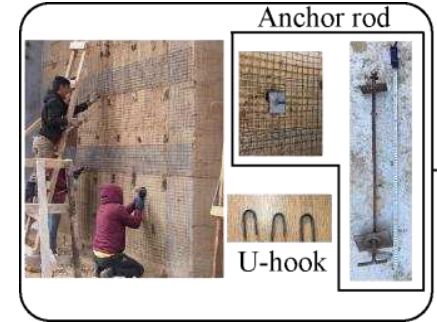

(a)

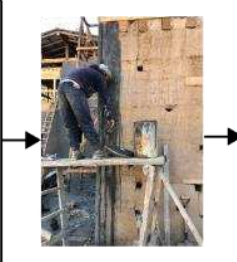

(b)

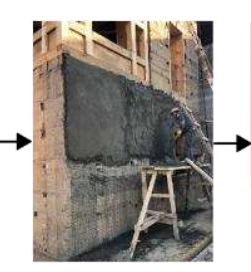

(c)

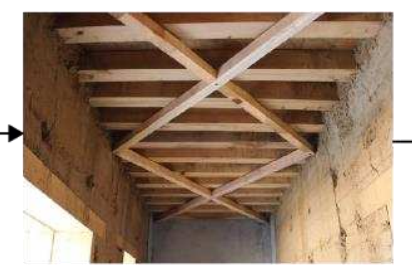

(d)

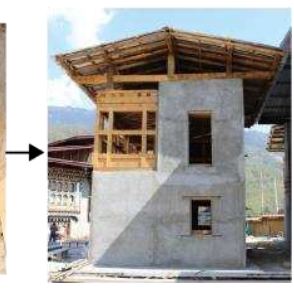

(e)

Figure 3: Retrofitting work process: (a) Placement and anchorage of mesh, (b) Application of cement slurry as pretreatment, (c) Cement plastering, (d) Wooden brace for floor rigidity, (e) Final specimen after retrofitting

The static test loading protocol involved the displacement controlled loading with control 
over the drift in the building. Each floor level of the specimen was subjected to displacement controlled loading to a specified target storey drift value, followed by observation of cracks and damages to the building. Here, the storey drift ratio, $\theta$, is the ratio of the lateral displacement to the floor height. Cracks and damage observations were done at the storey drift ratios of: 1/2000, $1 / 1000,1 / 750,1 / 500$ for the prototype unreinforced rammed earth specimen (URE). For retrofitted prototype specimen (RRE), in addition to above drift values, the building was subjected to storey drifts of $1 / 250,1 / 150,1 / 100$, and $1 / 75$. It should be noted that the loads applied in each storey levels, 2FL and RFL, were displacement controlled through manual synchronization, maintaining the target storey drifts through the monitoring of the drift records at the real-time data logging system. Figure $4 \mathrm{~b}$ shows the target and the actual storey drifts for the static test, and the actual loading history can be considered satisfactorily closer to the target drift. The load cell measurements and the absolute displacement readings were collected to draw the capacity curves for each test specimen.

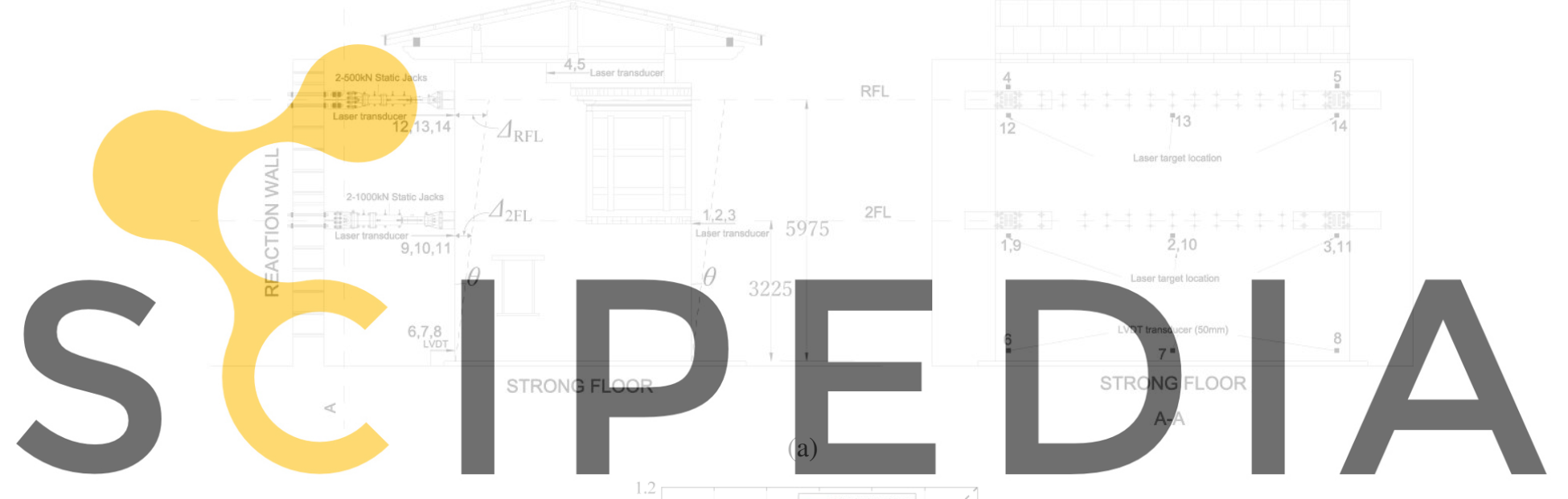

Register for free at https//www.scipedia.com to downløad the version without the watermark

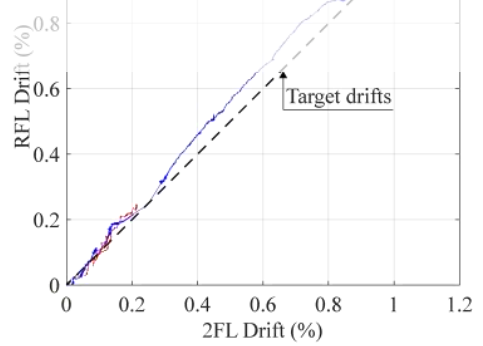

(b)

Figure 4: (a)Test set-up and instrumentation, (b) Actual and target storey drifts

\section{RESULTS AND DISCUSSION}

\subsection{Micro-tremor measurements for dynamic characterization}

Micro-tremor measurements for the test structures were made using three-component velocity sensor Model-2205B by Showa Sokki Corporation. The measurements were made to assess the vibrational characteristics of the prototype specimen before the test (no damage) and 
after the test (post damage) and also to study vibrational characteristics' changes after the retrofitting process. The data sampling was done at a frequency of $200 \mathrm{~Hz}$ with a recording time of 300 seconds. The measurements were done where the sensor pick-ups were placed at the 1FL, 2FL and RFL of the building specimen. Table 2 lists the first two natural frequencies for both the test specimens estimated using the Stochastic Subspace Identification (SSI) method. The first mode natural frequency for URE (before test) was $5.29 \mathrm{~Hz}$, and this reduced to 4.64 $\mathrm{Hz}$ after the test with moderate damage at maximum storey drift of 1/500. Similarly, with the retrofitting measures, the first mode natural frequency increased to $6.03 \mathrm{~Hz}$, which alsosubsequently reduced to $5.22 \mathrm{~Hz}$ after the test.

Table 2: Results from micro-tremor measurements

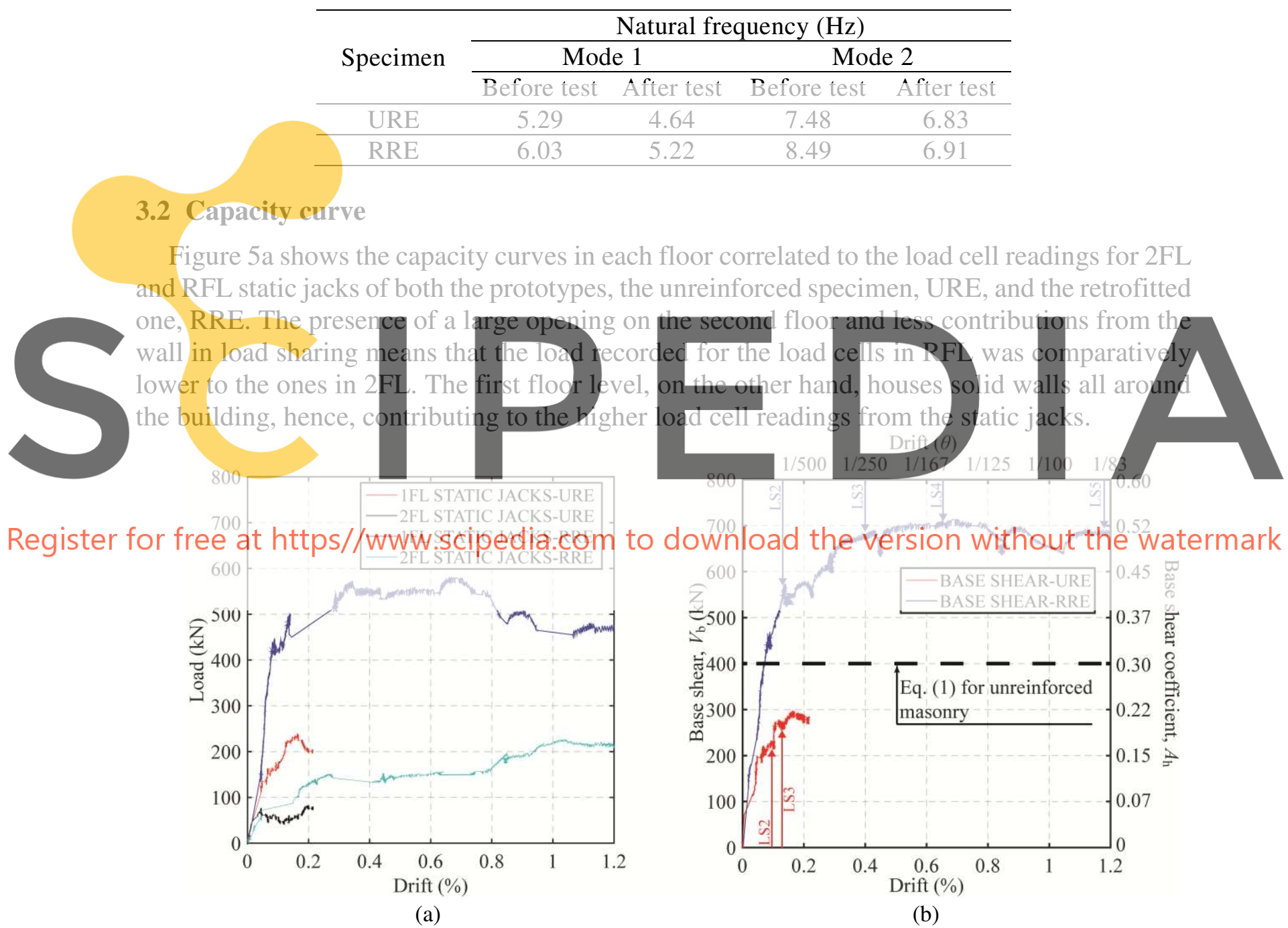

Figure 5: (a) Capacity curves in each floor for both prototype unreinforced and retrofitted specimens, (b) Global capacity curves for both prototype and retrofitted specimens

Figure 5b shows the global capacity curves with cumulative base shears of URE and RRE specimens. It should be noted that the drift $(\theta)$ shown in the capacity curves is the roof storey 
drift, defined as the absolute displacement of the roof (Sensors 12-14 in Figure 4a) divided by the height of the sensor from the ground. From the global capacity curves, the ultimate strength for RRE specimen $(714 \mathrm{kN})$ was about 2.4 times URE specimen $(294 \mathrm{kN})$, an increment of 420 $\mathrm{kN}$. Further, the roof displacement for RRE $(38.5 \mathrm{~mm})$ at the maximum base shear was about 4.2 times for URE (9 mm).

Indian Standard Code IS 1893 [7] provides simple formulations to compute design base shear for unreinforced masonry in the Indian subcontinent, which was for comparison purposes in Figure 5b, represented by dotted lines. The design base shear [7] is given by:

$$
V_{\mathrm{b}}^{\mathrm{D}}=A_{\mathrm{h}} W_{\mathrm{t}}
$$

where, $A_{\mathrm{h}}$ is the design horizontal base shear coefficient given by $\left(Z I S_{\mathrm{a}} / g\right) /(2 R)$ and $W_{\mathrm{t}}$ is the seismic weight of the building. Here, $Z$ is the zone factor taken as 0.36 for very severe seismic zone, $I$ is the importance factor taken as 1 for a residential building, $S_{\mathrm{a}} / g$ is the spectral acceleration coefficient taken as 2.5 for a natural time period of 0.2 second, and $R$ is the response reduction factor taken as 1.5. The cumulative base shear of URE was below the design base shear value, and the retrofitted specimen RRE exceeded the design value by 1.8 times.

There were also significant enhancements in ductility and energy absorption for the RRE specimen, as shown in Table 3. Here, the energy absorption $(\psi)$ is given by the area under the global capacity curve until the ultimate base shear, and the corresponding top storey displacement. Ductility is the ratio of top storey displacement at the ultimate base shear to yield displacement. It should be noted that the results reported for unreinforced specimen URE were

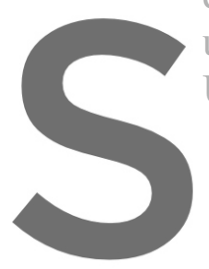
until the storey drift of $1 / 500$; hence the values
URE can be slightly underestimated.
Table 3: Test results for the prototyp
Specimen Ultimate base En shear, $V(\mathrm{kN})$
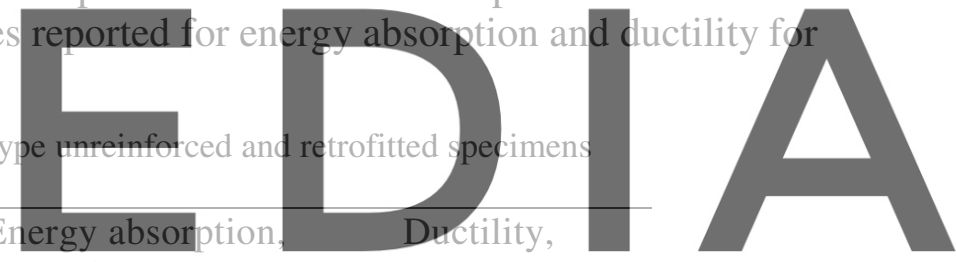

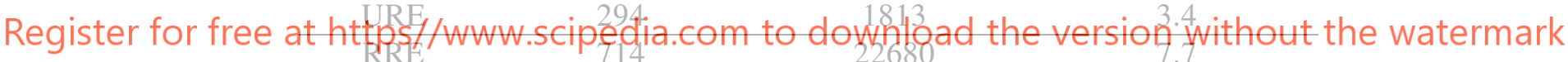

\subsection{Damage observations and definition of the limit states}

Real-time manual crack documentation was done during the test at the predefined target storey drift ratio through visual observations, and detailed drafting of the cracks was done at a later stage with the support of video recordings. The damage observations for the test specimens are illustrated in detail in Figure 6 for URE and Figure 7 for RRE. Here, cracks for in-plane walls in the loading direction are presented, and relatively smaller cracks for dispensable walls in out-of-plane are excluded.

The damage observed during the tests is also reflected in terms of limit states defined by five different predefined damage states, as illustrated in Table 4 . The limit states in Table 4 are modified form of the same proposed by Nabouch et al. [8] for rammed earth walls, based on in-plane shear tests on individual rammed earth walls. Since the present study is on a full-scale structure, the proposed limit states are also more practical and representative of the actual real scale building. 
Kshitij C. Shrestha, Takayoshi Aoki, Mitsuhiro Miyamoto, Noriyuki Takahashi, Jingyao Zhang, Phuntsho Wangmo, Noboru Yuasa, Sangchul Shin, Pema and Kunzang Tenzin

Table 4: Limit states for rammed earth building

\begin{tabular}{ccc}
\hline Limit states & Damage & Observations in the building \\
\hline LS1 & No damage & No crack observed \\
\hline LS2 & Slight damage & First appearance of cracks \\
\hline LS3 & Moderate damage & $\begin{array}{c}\text { Cracks near openings (diagonal cracks); Toe crushing; } \\
\text { First observation of fall of earth particles }\end{array}$ \\
\hline LS4 & Extensive damage & $\begin{array}{c}\text { Extension of diagonal cracks; Extensive crushing; } \\
\text { Extensive fall of earth particles }\end{array}$ \\
\hline LS5 & Total collapse & $\begin{array}{c}\text { Excessive damage not economically reparable; Visible } \\
\text { residual drift }\end{array}$ \\
\hline
\end{tabular}

\subsubsection{Unreinforced rammed earth specimen (URE)}

For URE specimen, the crack documentation, as illustrated in Figure 6 are presented for three storey drifts, 1/1000, 1/750 and 1/500. As reported earlier, the test was stopped at the drift of 1/500 for later retrofitting purposes and re-testing of the same building. The first few hairline cracks originated near door openings and below the loading point in east elevation, and near lintel and jugshing holes of west elevation when the storey drift was up to 1/1000 (Limit sate: LS2 Slight damage). For the storey drift of 1/750, there was an extension of cracks in the in-plane walls and new cracks were visible within the rammed earth blocks in 1FL (Limit sate: LS3 Moderate damage). At 1/500 storey drift, there was a widening of the previous cracks and

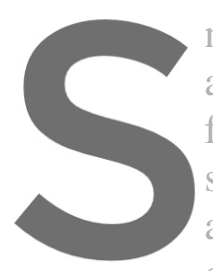
new inclined shear cract about $1.5 \mathrm{~m}$ long also app falling (Limit sate: substantial damage to aim was to retrofit this building for re-testing
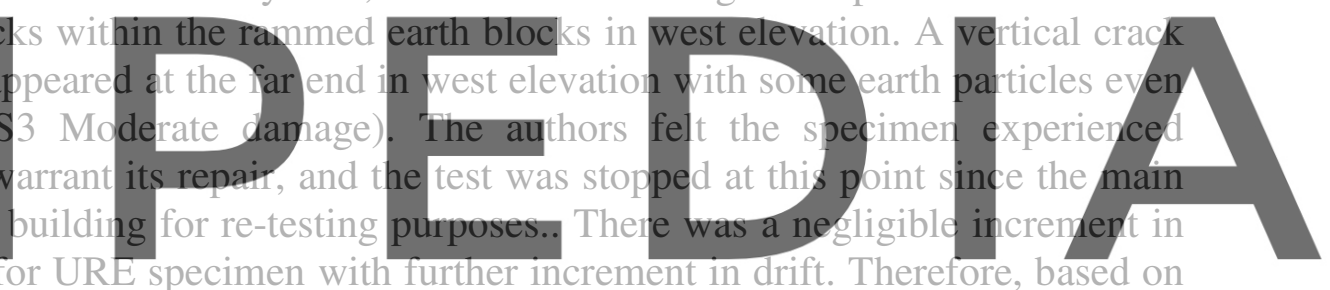

cumulative base shear for URE specimen with further increment in drift. Therefore, based on authors"observations, limit state of.LS4 representing "Extensive damage" will possibly occur

\subsubsection{Retrofitted rammed earth specimen ( $R R E)$}

The crack documentation for RRE specimen is illustrated in Figure 7 for six different storey drift levels with their corresponding damage states defined. There were no cracks observed up to storey drift of 1/1000 (Limit sate: LS1 No damage). At storey drifts of 1/750 and 1/500, hairline cracks started to appear near the lintels of openings. There were also numerous small vertical cracks below the rabsey opening corner, and horizontal cracks also initiated in both floor levels (Limit sate: LS2 Slight damage). It should be noted that all the cracks were hairline cracks up to this load level. For storey drift of $1 / 250$, there was widening and extension of previous cracks at the corner of rabsey opening and clear vertical cracks at the far end from the loading point. There was also crack due to toe crushing near the base of the south face (Limit sate: LS3 Moderate damage). At storey drift of 1/150, there were extensive cracks and slight spalling of plaster (Limit sate: LS4 Extensive damage), with a clear long horizontal crack along the sill level, possibly the lapping region of the mesh. The previous cracks kept extending for storey drift of $1 / 100$, followed by extensive spalling of plaster above the door opening (2FL) and also near the window opening (1FL). There was also plaster crushing at the toe near the 
base of the south face (Limit sate: LS4 Extensive damage). At storey drift of 1/75, the cracks opened up significantly wide, and these relatively wide cracks were extending over the whole length of the wall. The spalling of plaster continued, and clear rocking of the entire building was visible. A sharp splitting sound possibly due to the dislocation of timber components was heard. Furthermore, the building also showed clear residual drift post the release of load. Based on the observation, this limit state level was defined as LS5 Near collapse. It should be noted that there was no delamination or separation of the mesh from the specimen throughout the whole test, showing the effectiveness of the anchor rods in keeping the mesh intact even at such adverse damage levels.

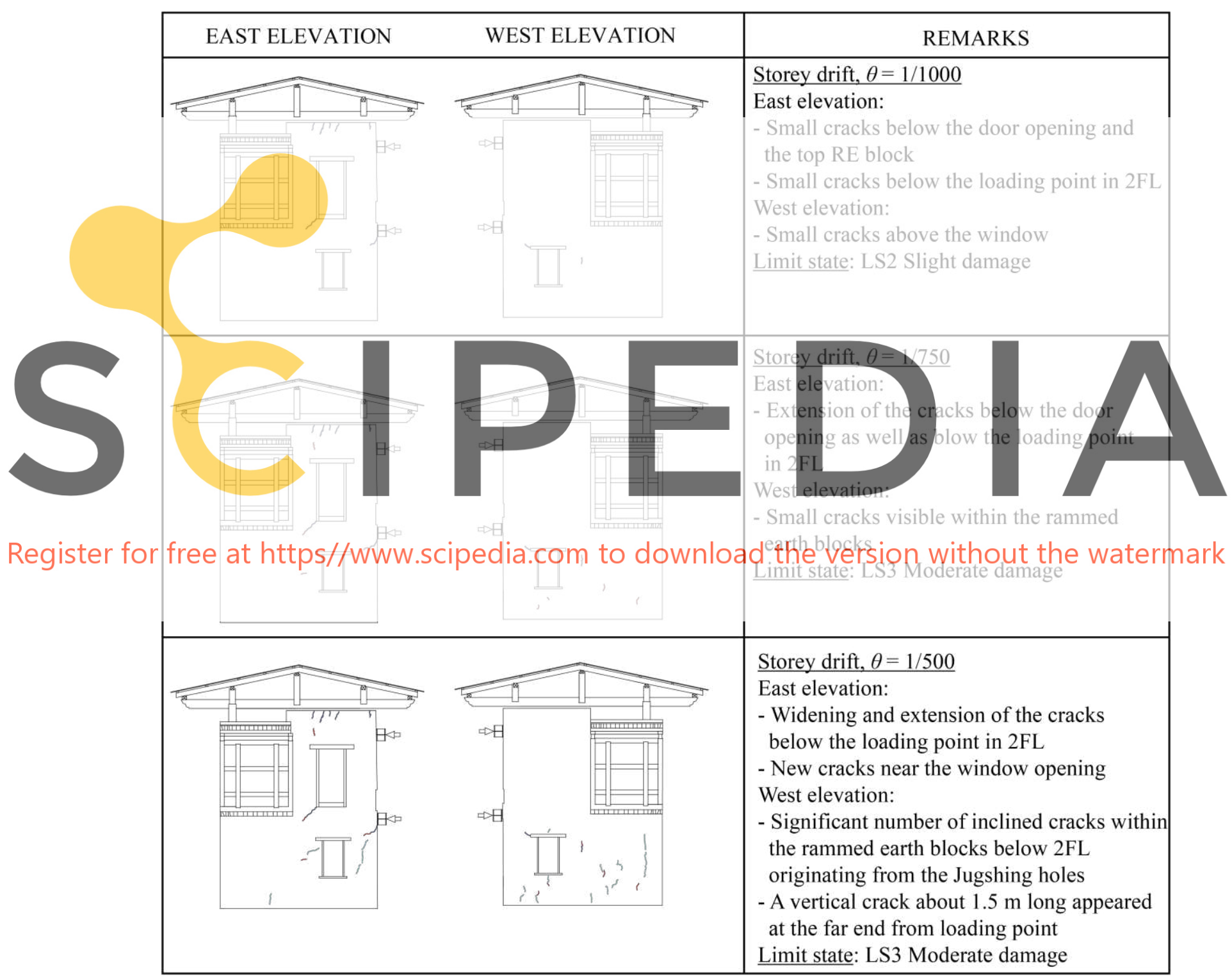

Figure 6: Crack evolution for unreinforced rammed earth (URE) specimen at different load levels and their respective limit states 
Kshitij C. Shrestha, Takayoshi Aoki, Mitsuhiro Miyamoto, Noriyuki Takahashi, Jingyao Zhang, Phuntsho Wangmo, Noboru Yuasa, Sangchul Shin, Pema and Kunzang Tenzin

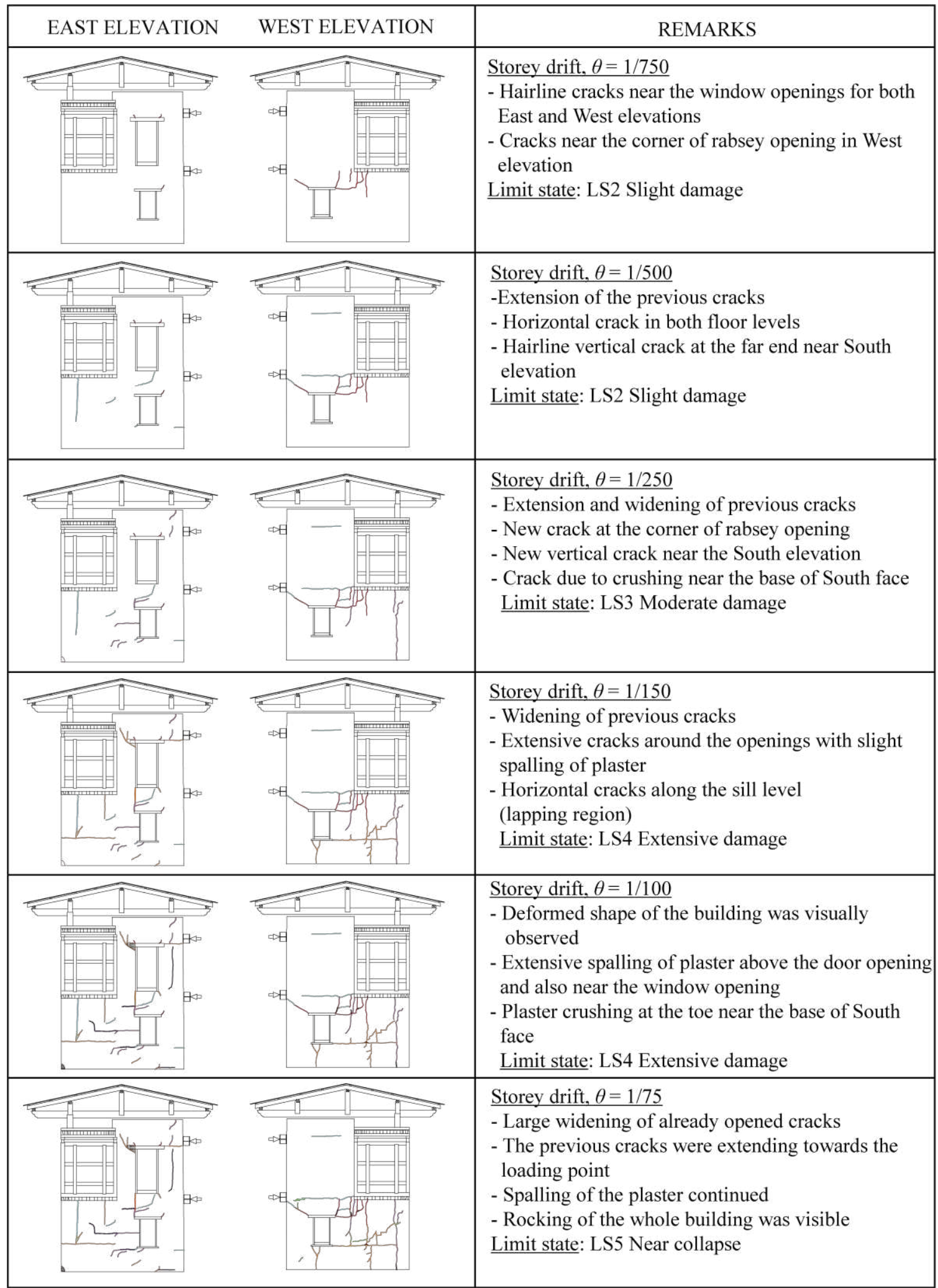

Figure 7: Crack evolution for mesh-retrofitted rammed earth (RRE) specimen at different load levels and their respective limit states 


\section{CONCLUSIONS}

In the context of understanding the vulnerabilities of traditional rammed earth structure and proposing an effective retrofitting strategy, a full-scale static test was designed on a typical prototype two-storied Bhutanese rammed earth building. The test program involved two phases of testing, with the first test on unreinforced rammed earth specimen (URE) and the second phase with the test on the same building after mesh-wrap retrofitting (RRE). The ultimate base shear for RRE was 2.4 times of URE. The energy absorption and ductility index were also significantly enhanced for mesh-wrap retrofitted specimen by 12 and 2.3 times, respectively.

Damage limit states for the prototype rammed earth building is also presented to understand the evolution of damage in rammed earth structure at different storey drifts based on real-scale test results. A set of five limit state values are proposed as a function of storey drift ratios, with a clear definition of the damage levels and damage states visually understandable for both unreinforced and retrofitted rammed earth building.

Acknowledgements. This research was supported by the JST/JICA, SATREPS (Science and Technology Research Partnership for Sustainable Development) project (Grant No. JPMJSA1611). We would also like to acknowledge the technical assistance of Engineer Ugyen Dorji and Technician Lhendup from DoC, MOHCA, The Royal Government of Bhutan.

\section{REFERENCES}

[1] Hamilton, H.R., McBride, J. and Grill, J. Cyclic testing of rammed-earth walls containing post-tensioned reinforcement. Earthquake Spectra (2006) 22:937-959.

[2] Miccoli, L., Oliviera, D.V., Silva, R.A., Muller, U. and Schueremans, L. Static behaviour of rammed earth: experimental testing and finite element modelling. Materials and Structures (2014) 48:3443-3456.

[3] Wangmo, P., Shrestha, K.C., Miyamoto, M. and Aoki, T. Assessment of out-of-plane behavior of rammed earth walls by pull-down tests. International Journal of Architectural Heritage (2019) 13:273-287

[4] Shrestha, K.C., Aoki, T., Konishi, T., Miyamoto, M., Zhang, J., Takahashi, N., Wangmo, P., Aramaki, T. and Yuasa, N. Full-Scale Pull-Down Tests on a Two-Storied Rammed Earth Building with Possible Strengthening Interventions. In: R. Aguilar et al. (Eds.): Structural Analysis of Historical Constructions, RILEM Bookseries 18 (2019), pp. 15571565.

[5] Shrestha, K.C., Aoki, T., Miyamoto, M., Wangmo, P., Pema, Zhang, J. and Takahashi, N. Strengthening of rammed earth structures with simple interventions. Journal of Building Engineering (2020) 29:101179.

[6] Shrestha, K.C., Aoki, T., Miyamoto, M., Wangmo, P. and Pema. In-plane shear resistance between the rammed earth blocks with simple interventions: Experimentation and finite element study. Buildings (2020) 10:57.

[7] Indian Standard 1893 Part 1. Indian Standard Criteria for earthquake resistant design of structures Part 1 General provisions and buildings, Bureau of Indian Standards, 5th edition, (2002).

[8] El Nabouch, R., Bui, Q.B., Ple, O. and Perrotin, P. Rammed earth under horizontal loadings: Proposition of limit states. Construction and Building Materials (2019) 220:238-244. 